\title{
Fabrication of hollow coaxial Al2O3/ZnAl2O4 high aspect ratio freestanding nanotubes based on the Kirkendall effect
}

Shkondin, Evgeniy; Alimadadi, Hossein; Takayama, Osamu; Jensen, Flemming; Lavrinenko, Andrei V.

Published in:

Journal of Vacuum Science and Technology A: Vacuum, Surfaces and Films

Link to article, DOI:

$10.1116 / 1.5130176$

Publication date:

2020

Document Version

Publisher's PDF, also known as Version of record

Link back to DTU Orbit

Citation $(A P A)$ :

Shkondin, E., Alimadadi, H., Takayama, O., Jensen, F., \& Lavrinenko, A. V. (2020). Fabrication of hollow coaxial $\mathrm{Al}_{2} \mathrm{O}_{3} / \mathrm{ZnAl}_{2} \mathrm{O}$ high aspect ratio freestanding nanotubes based on the Kirkendall effect. Journal of Vacuum Stience and Téchnology A: Vacuum, Surfaces and Films, 38(1), [013402]. https://doi.org/10.1116/1.5130176

\section{General rights}

Copyright and moral rights for the publications made accessible in the public portal are retained by the authors and/or other copyright owners and it is a condition of accessing publications that users recognise and abide by the legal requirements associated with these rights.

- Users may download and print one copy of any publication from the public portal for the purpose of private study or research.

- You may not further distribute the material or use it for any profit-making activity or commercial gain

- You may freely distribute the URL identifying the publication in the public portal 


\section{Fabrication of hollow coaxial $\mathrm{Al}_{2} \mathrm{O}_{3} / \mathrm{ZnAl}_{2} \mathrm{O}_{4}$ high aspect ratio freestanding nanotubes based on the Kirkendall effect}

Evgeniy Shkondin, Hossein Alimadadi, Osamu Takayama, Flemming Jensen, and Andrei V. Lavrinenko

Citation: Journal of Vacuum Science \& Technology A 38, 013402 (2020); doi: 10.1116/1.5130176

View online: https://doi.org/10.1116/1.5130176

View Table of Contents: https://avs.scitation.org/toc/jva/38/1

Published by the American Vacuum Society

\section{ARTICLES YOU MAY BE INTERESTED IN}

Thermal atomic layer deposition of ruthenium metal thin films using nonoxidative coreactants Journal of Vacuum Science \& Technology A 38, 012402 (2020); https://doi.org/10.1116/1.5125109

Surface reaction mechanisms during atomic layer deposition of zirconium oxide using water, ethanol, and waterethanol mixture as the oxygen sources

Journal of Vacuum Science \& Technology A 38, 012401 (2020); https://doi.org/10.1116/1.5122994

Role of template layers for heteroepitaxial growth of lanthanum oxide on $\mathrm{GaN}(0001)$ via atomic layer deposition Journal of Vacuum Science \& Technology A 38, 012403 (2020); https://doi.org/10.1116/1.5131638

Review Article: Atomic layer deposition of doped $\mathrm{ZnO}$ films Journal of Vacuum Science \& Technology A 37, 050802 (2019); https://doi.org/10.1116/1.5112777

Textured growth of polycrystalline MAX phase carbide coatings via thermal annealing of M/C/Al multilayers Journal of Vacuum Science \& Technology A 38, 013401 (2020); https://doi.org/10.1116/1.5131544

Temperature-dependence of $\mathrm{Cl}_{2} / \mathrm{Ar}$ ICP-RIE of polar, semipolar, and nonpolar $\mathrm{GaN}$ and $\mathrm{AIN}$ following $\mathrm{BCl}_{3} / \mathrm{Ar}$ breakthrough plasma Journal of Vacuum Science \& Technology A 38, 013001 (2020); https://doi.org/10.1116/1.5123787

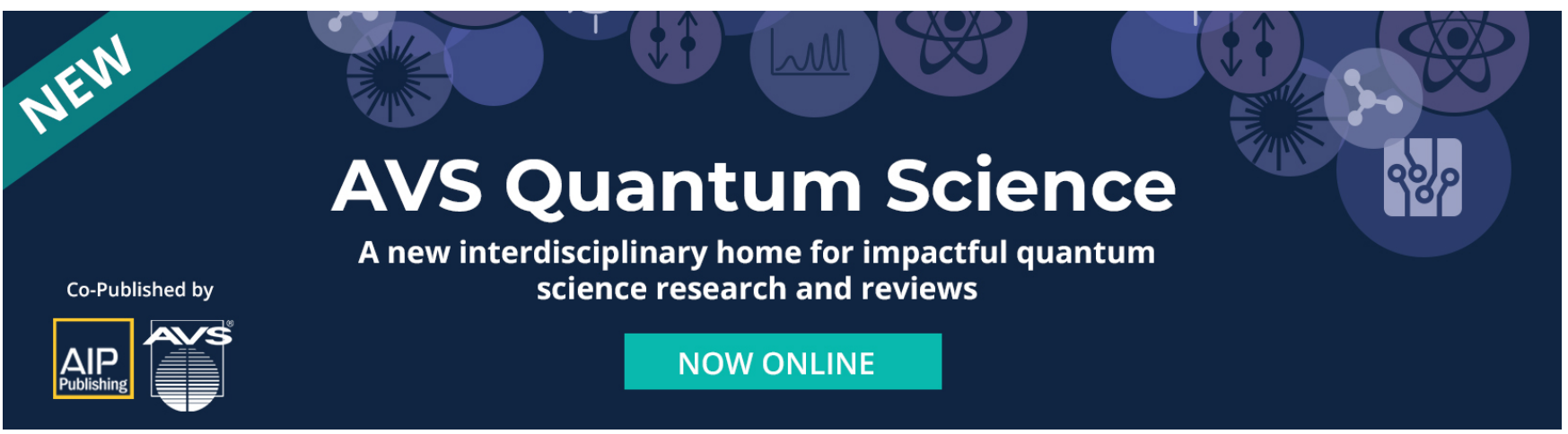




\title{
Fabrication of hollow coaxial $\mathrm{Al}_{2} \mathrm{O}_{3} / \mathrm{ZnAl}_{2} \mathrm{O}_{4}$ high aspect ratio freestanding nanotubes based on the Kirkendall effect
}

Cite as: J. Vac. Sci. Technol. A 38, 013402 (2020); doi: 10.1116/1.5130176

Submitted: 3 October 2019 - Accepted: 12 November 2019 .

Published Online: 17 December 2019

Evgeniy Shkondin, ${ }^{1,2, a)}$ (D) Hossein Alimadadi, ${ }^{2,3}$ Osamu Takayama, ${ }^{1}$ Flemming Jensen, ${ }^{2}$ and Andrei V. Lavrinenko

\author{
AFFILIATIONS \\ ${ }^{7}$ Department of Photonics Engineering, Technical University of Denmark, DK-2800 Kgs. Lyngby, Denmark \\ ${ }^{2}$ National Centre for Nano Fabrication and Characterization (DTU Nanolab), DK-2800 Kgs. Lyngby, Denmark \\ ${ }^{3}$ Danish Technological Institute, DK-8000 Aarhus C, Denmark
}

${ }^{a)}$ Electronic mail: eves@dtu.dk

\begin{abstract}
In this communication, fabrication of high aspect ratio $\mathrm{Al}_{2} \mathrm{O}_{3} / \mathrm{ZnO} / \mathrm{Al}_{2} \mathrm{O}_{3}$ nanotubes is reported and morphological changes at elevated temperatures are investigated. The structures were made by implementing several fabrication methods, such as deep-UV lithography, atomic layer deposition (ALD), and plasma etch methods. During the fabrication, the ALD deposited $\mathrm{Al}_{2} \mathrm{O}_{3}$ and $\mathrm{ZnO}$ conformally passivated the prepared Si-holes template, resulting in the complex coaxial $\mathrm{Al}_{2} \mathrm{O}_{3} / \mathrm{ZnO} / \mathrm{Al}_{2} \mathrm{O}_{3}$ pillars. By utilizing several scanning and transmission electron microscopy techniques, it is experimentally shown that at elevated temperatures, internal voids form in the nanotube due to diffusion of $\mathrm{ZnO}$ into surrounding $\mathrm{Al}_{2} \mathrm{O}_{3}$ and also $\mathrm{ZnAl}_{2} \mathrm{O}_{4}$ spinel structure forms. Finally, the porous tubes have been isolated from the surrounding silicon core using a conventional isotropic selective Si plasma etch process. The presented approach opens the opportunity to build complex optical metamaterial compositions, for example, for a new generation of sensors for gas and biomarker detection.
\end{abstract}

Published under license by AVS. https://doi.org/10.1116/1.5130176

\section{INTRODUCTION}

Current progress in optical metamaterials, i.e., artificially engineered materials, ${ }^{1}$ has emphasized the significance of developing the fabrication approach that would allow patterning high-quality optical materials at the nanoscale. Far-field imaging with super-resolution, ${ }^{2,3}$ materials with hyperbolic dispersion, ${ }^{4-6}$ and optical cloaking ${ }^{1}$ are only a few examples among many different topics that require the realization of highly ordered, periodic metal-dielectric threedimensional structures with deep subwavelength feature sizes. The topology of metamaterials and metasurfaces typically consists of an array of nanopillars, ${ }^{7-9}$ trenches, $^{10,11}$ and flat multilayers ${ }^{12-15}$ in the simplest forms. The realization of multicoaxial cylindrical structures enables the development of new promising materials with extraordinary and exciting responses to light, which includes hyperbolic ${ }^{16}$ and all-dielectric metamaterials. ${ }^{17}$ Additionally, such structures are excellent candidates for a new generation of gas and biological sensors, where the response based on the extremely large surface area of active materials can be enhanced further by hyperbolic light dispersion. ${ }^{1,4,7,14,18-20}$ One method to change the surface area and tune the optical response is to use solid-state interface diffusion and the associated phenomena such as the Kirkendall effect. Different interface reactions have been reported so far, which include $\mathrm{ZnO}-\mathrm{TiO}_{2},{ }^{21} \mathrm{ZnO}-\mathrm{SiO}_{2},{ }^{22} \mathrm{MgO}-\mathrm{Al}_{2} \mathrm{O}_{3},{ }^{23}$ etc. Recent reports pointed out the possible Kirkendall effect in $\mathrm{Al}_{2} \mathrm{O}_{3} / \mathrm{ZnO}$ nanolaminates. ${ }^{24-26}$ During annealing, the diffusion of $\mathrm{ZnO}$ into $\mathrm{Al}_{2} \mathrm{O}_{3}$ leads to the formation of crystalline $\mathrm{ZnAl}_{2} \mathrm{O}_{4}$ spinel. In general, this solid-state reaction is highly sensitive to annealing temperature, annealing time, layer thickness, and other parameters.

This work presents a fabrication approach of freestanding high aspect ratio, hollow coaxial nanotubes, where $\mathrm{Al}_{2} \mathrm{O}_{3} / \mathrm{ZnO} /$ $\mathrm{Al}_{2} \mathrm{O}_{3}$ coatings exhibit a solid-state diffusion reaction, which transforms $\mathrm{ZnO}-\mathrm{Al}_{2} \mathrm{O}_{3}$ interfaces into porous $\mathrm{ZnAl}_{2} \mathrm{O}_{4}$ spinel nanocrystals. The Kirkendall effect can be used in the realization of a new class of advanced optical metamaterials, where the porous structure inside the tube can significantly increase the surface area facilitating enhanced sensitivity toward analyzed targets. 


\section{EXPERIMENT}

\section{A. Fabrication details}

The nanopillars were fabricated by combining deep-UV lithography, atomic layer deposition (ALD), ${ }^{27-29}$ and advanced deep reactive ion etching (DRIE) techniques. ${ }^{30} \mathrm{~A}$ similar approach has been developed recently for the fabrication of high aspect ratio Al-doped $\mathrm{ZnO}$ (AZO) pillars, ${ }^{9}$ deep trenches made of $\mathrm{Al}_{2} \mathrm{O}_{3}$, $\mathrm{TiO}_{2}{ }^{31} \mathrm{TiN}^{18}$ and $\mathrm{ZnO}{ }^{20}$ The method is based on ALD deposition on high aspect ratio silicon structures (mold) with subsequent selective removal of the silicon template, leaving a negative replica of the template structure in the functional material.

ALD is the only technique that can produce such coatings, all other known methods such as pulsed laser deposition, CVD, or sputtering suffer from poor step coverage and nonuniformity. ${ }^{28}$ The use of ALD in combination with a sacrificial silicon mold is a novel method to create high aspect ratio metal oxide structures. Figure 1 shows the fabrication steps in the pillars patterning. Starting from the substrate deep-UV lithography and DRIE template preparation [Figs. 1(a)-1(c)], the fabrication continues with ALD deposition, top layer $\mathrm{Ar}^{+}$ion sputtering, and annealing [Figs. 1(d)-1(f)]. The last step is silicon template removal, which was done by an isotropic $\mathrm{SF}_{6}$ plasma reactive ion etching (RIE) [Fig. 1(g)]. The success of this procedure is heavily dependent on the ability to etch silicon selectively, without affecting the ALD coatings. It is noteworthy that no distortion of the pillars was observed after template removal in the last step.

\section{Si hole-array template preparation}

Homemade silicon-on-insulator (SOI) wafers [Fig. 1(a)] were used for the entire fabrication procedure. First, $150 \mathrm{~mm}$ (100) Si wafers were selected, and the wafers were RCA cleaned and later oxidized to achieve $200 \mathrm{~nm}$ thick $\mathrm{SiO}_{2}$ in a conventional quartz tube furnace (from Tempress) using a dry oxidation process based on $\mathrm{O}_{2}$ at $1100^{\circ} \mathrm{C}$. Afterward, $2 \mu \mathrm{m}$ polycrystalline silicon was deposited on the $\mathrm{SiO}_{2}$ surface using a low vapor chemical vapor deposition (LPCVD) technique based on $\mathrm{SiH}_{4}$, which was carried out at $560^{\circ} \mathrm{C}$ (furnace from Tempress). Surface roughness was characterized by atomic force microscopy, which revealed that surface roughness is below $1 \mathrm{~nm}$, validating the use of the SOI wafers as an Si template.

A square lattice of holes [Fig. 1(b)] with a diameter of $300 \mathrm{~nm}$ and a lattice constant of $400 \mathrm{~nm}$ was patterned using deep-UV lithography on a square chip $\left(1 \times 1 \mathrm{~cm}^{2}\right)$ of SOI wafer. The procedure consists of a bottom antireflective coating (BARC), photoresist coating, exposure, postbake, and development. To minimize interference effects and promote adhesion, the substrate surface was coated (Süss MicroTec Gamma 2M spin coater) with a $65 \mathrm{~nm}$ thick BARC coating (DUV42S-6, Brewer Science, USA) followed by a a) SOI substrate

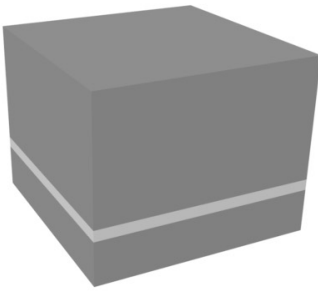

d)

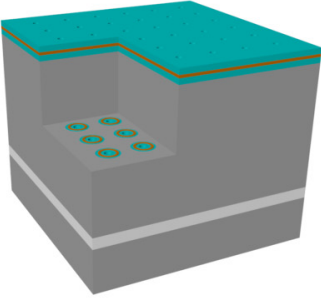

g) Si template removal

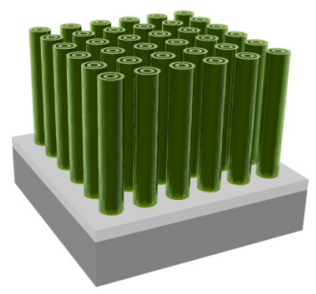

b) Deep-UV lithography
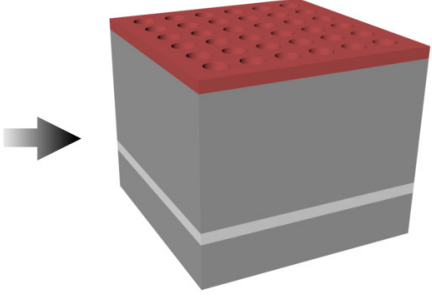

e) $\quad \mathrm{Ar}^{+}$sputtering
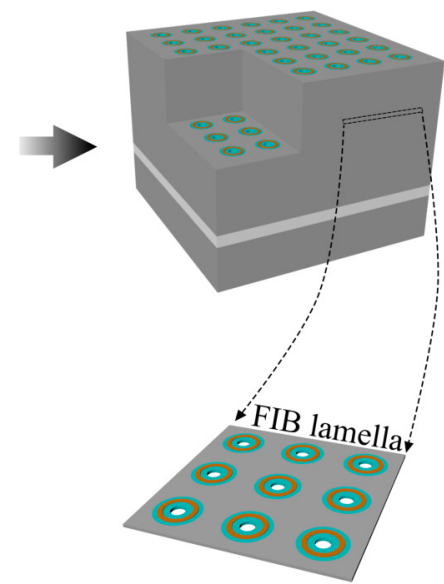

c)

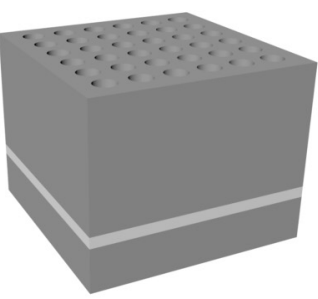

f) Annealing

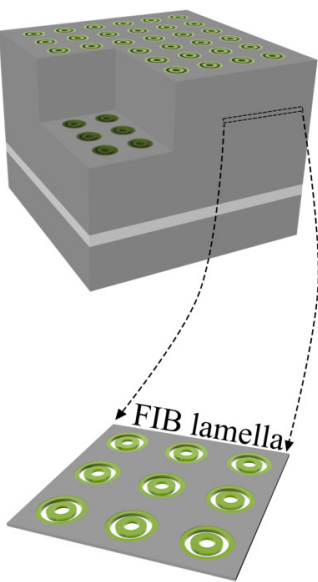

FIG. 1. Fabrication flow. (a) SOI substrates. (b) Deep-UV lithography. (c) Square lattice holes arrays in the silicon substrate as a template prepared by DRIE. (d) Deposition of $\mathrm{Al}_{2} \mathrm{O}_{3} / \mathrm{ZnO} / \mathrm{Al}_{2} \mathrm{O}_{3}$ using ALD. (e) Sputtering of ALD deposited cap layers. (f) Annealing of the structure at $800^{\circ} \mathrm{C}$. (g) Isolation of pillars by etching of the silicon template. 
TABLE I. DRIE parameters for template fabrication.

\begin{tabular}{|c|c|c|c|}
\hline & & Passivation $(1.5 \mathrm{~s})$ & Etching $(2.75 \mathrm{~s})$ \\
\hline \multirow[t]{3}{*}{ Process gas flow $(\mathrm{sccm})$} & $\mathrm{C}_{4} \mathrm{~F}_{8}$ & 50 & 20 \\
\hline & $\mathrm{SF}_{6}$ & - & 60 \\
\hline & $\mathrm{O}_{2}$ & - & 5 \\
\hline \multirow[t]{2}{*}{ Powers (W) } & Coil & 600 & 400 \\
\hline & Platen & - & 40 \\
\hline
\end{tabular}

bake-out at $175^{\circ} \mathrm{C}$ for $60 \mathrm{~s}$. Then, a positive photoresist (KRF M230Y, JSR Micro, NV) was spin-coated to a thickness of $360 \mathrm{~nm}$ and baked at $130^{\circ} \mathrm{C}$ for $90 \mathrm{~s}$. Next, the SOI wafer with resist coatings was exposed (an exposure dose of $860 \mathrm{~J} / \mathrm{m}^{2}$ ) on field sizes of $1 \times 1 \mathrm{~cm}^{2}$ (Canon FPA-3000 EX4 DUV stepper). The last lithography step was $90 \mathrm{~s}$ postexposure bake at $130{ }^{\circ} \mathrm{C}$ followed by developing in $2.38 \%$ tetramethylammonium hydroxide solution for $90 \mathrm{~s}$ (Süss MicroTec Gamma 2M developer).

DRIE etching (DRIE Pegasus from SPTS) was completed in a switched Bosch process consisting of cyclic steps of etching and passivation [Fig. 1(c)]. During etching, the wafer chuck was held constantly at $0{ }^{\circ} \mathrm{C}$, and the process pressure was fixed at $10 \mathrm{~m}$ Torr. Three main steps were implemented for the Si template fabrication: etching of the BARC layer, high anisotropic silicon etching for template preparation (Table I summarizes the Bosch parameters), and remaining resist plasma ashing. The BARC etch proceeds for $45 \mathrm{~s}$ using $40 \mathrm{sccm} \mathrm{O}_{2}$ plasma with coil and platen powers of 400 and $20 \mathrm{~W}$, respectively. In the following Bosch process, the depth of the holes was controlled by correcting the number of cycles ( 85 cycles correspond approximately to $2 \mu \mathrm{m}$ deep holes). The strict control is less important in this case since etching basically stops when reaching the $\mathrm{SiO}_{2}$ layer in the SOI substrates. The depth of the holes is limited to the LPCVD deposited $\mathrm{Si}$, which is, in this case, $2 \mu \mathrm{m}$. For deeper profiles that require a thicker Si top layer, a modification of the Bosch process presented in Table I needs to be made as well. Nowadays, the achievable etch depth is comparable to wafer thickness, as more advanced versions of the Bosch process have been developed. ${ }^{32,33}$ The last phase of template fabrication is the removal of the resist leftovers, which was done using an $\mathrm{O}_{2}$ plasma for $2 \mathrm{~min}$ with the flow of $100 \mathrm{sccm}$. The coil and platen powers were $800 \mathrm{~W}$ and $20 \mathrm{~W}$, respectively. The shape and morphology of the produced Si-holes template structures were carefully inspected by scanning electron microscopy (SEM, Supra 60VP from Zeiss) in the cross-sectional mode by sacrificing some of the prepared structures. The achieved diameter of the holes is indeed very close to $300 \mathrm{~nm}$ despite imperfections in the etching procedure. Prior to the next step (ALD deposition), the prepared Si template hole-array structures received an additional $\mathrm{O}_{2} / \mathrm{N}_{2}$ plasma treatment for approximately $20 \mathrm{~min}$ in order to eliminate any possible remaining organic residuals from resist coatings and surroundings.

\section{Atomic layer deposition}

Next, the holes were filled with $\mathrm{Al}_{2} \mathrm{O}_{3} / \mathrm{ZnO} / \mathrm{Al}_{2} \mathrm{O}_{3}$ layers (thicknesses of 50/25/50 nm, respectively) by ALD [Fig. 1(d)]. The deposition was carried out in a commercial hot-wall ALD system
TABLE II. Recipe for one cycle of $\mathrm{Al}_{2} \mathrm{O}_{3}$.

\begin{tabular}{lccc}
\hline \hline Precursor & $\begin{array}{c}\text { Carrier gas }\left(\mathrm{N}_{2}\right) \text { flow } \\
(\mathrm{sccm})\end{array}$ & Pulse time (s) & $\mathrm{N}_{2}$ purge (s) \\
\hline TMA & 150 & 0.1 & 0.5 \\
TMA & 150 & 0.1 & 20 \\
$\mathrm{H}_{2} \mathrm{O}$ & 200 & 0.1 & 0.5 \\
$\mathrm{H}_{2} \mathrm{O}$ & 200 & 0.1 & 20 \\
\hline \hline
\end{tabular}

(Picosun R-200) using diethyl zinc (DEZ), trimethylaluminum (TMA), and water as precursors at $200^{\circ} \mathrm{C}$. The ALD technique is the ideal choice for precise thickness control and conformal deposition of high aspect ratio structures. The recipes used in this work are presented in Tables II and III. Prior to deposition on the $\mathrm{Si}$ hole template, the deposition rates of $\mathrm{Al}_{2} \mathrm{O}_{3}$ and $\mathrm{ZnO}$ were defined by measuring thicknesses of $\mathrm{Al}_{2} \mathrm{O}_{3}$ and $\mathrm{ZnO}$ coatings on flat substrates with spectroscopic ellipsometry (VASE, J. A. Woolam Co.). The deposition rate for $\mathrm{Al}_{2} \mathrm{O}_{3}$ and $\mathrm{ZnO}$ at $200^{\circ} \mathrm{C}$ was found to be 0.09 and $0.15 \mathrm{~nm} /$ cycle, respectively, which is in good agreement with the previously reported values. ${ }^{27,34}$

\section{Ion beam etching and annealing}

The cap of the ALD layers on top of the structures was removed using $\mathrm{Ar}^{+}$ion milling (Ionfab 300 Plus from Oxford Instrument), thereby exposing the silicon matrix between deposited pillars [Fig. 1(e)]. The etching process of $\mathrm{ZnO}$ and $\mathrm{Al}_{2} \mathrm{O}_{3}$ was tuned to approximately 16 and $3.5 \mathrm{~nm} / \mathrm{min}$, respectively, which guaranteed well-controlled top layer sputtering. Prepared samples were annealed (furnace PEO-604 from ATV Technology) at $800{ }^{\circ} \mathrm{C}$ for $12 \mathrm{~h}$ in an $\mathrm{N}_{2}$ environment at atmospheric pressure in order to induce diffusion [Fig. 1(f)]. SEM images [Figs. 2(a) and 2(b)] reveal surface morphology before and after the annealing from which it is clearly seen [inset in Fig. 3(b)] that $\mathrm{ZnO}$ migrated into $\mathrm{Al}_{2} \mathrm{O}_{3}$ areas resulting in the formation of large voids.

\section{Focus ion beam lamella extraction}

In order to study structural evolution inside the pillars in detail by transmission electron microscopy (TEM), it was necessary to prepare thin lamellae of the pillars cross section. This was carried out using an in situ lift out by focus ion beam (FIB) in an SEM (FEI Helios NanoLab 600 Dual Beam system). To study the evolution, two electron transparent lamellae before and after annealing,

TABLE III. Recipe for one cycle of ZnO.

\begin{tabular}{lccc}
\hline \hline Precursor & $\begin{array}{c}\text { Carrier gas }\left(\mathrm{N}_{2}\right) \text { flow } \\
(\mathrm{sccm})\end{array}$ & Pulse time (s) & $\mathrm{N}_{2}$ Purge (s) \\
\hline $\mathrm{DEZ}$ & 150 & 0.1 & 0.5 \\
$\mathrm{DEZ}$ & 150 & 0.1 & 20 \\
$\mathrm{H}_{2} \mathrm{O}$ & 200 & 0.1 & 0.5 \\
$\mathrm{H}_{2} \mathrm{O}$ & 200 & 0.1 & 20 \\
\hline \hline
\end{tabular}



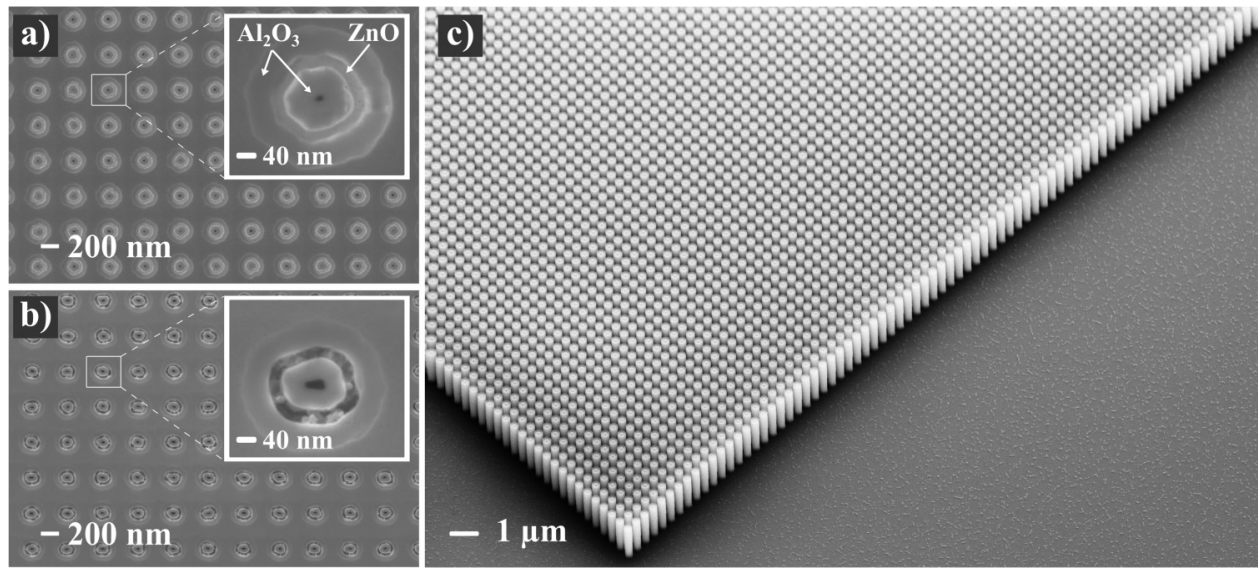

FIG. 2. Fabricated coaxial pillars. (a) Surface directly after ion beam etching. The inset shows the clear boundary between ALD deposited $\mathrm{Al}_{2} \mathrm{O}_{3}$ and $\mathrm{ZnO}$. (b) Sample surface after annealing at $800^{\circ} \mathrm{C}$. The inset shows the magnified image illustrating $\mathrm{ZnO}$ migration toward $\mathrm{Al}_{2} \mathrm{O}_{3}$. (c) Bird's-eye-view SEM image of isolated tubes standing on $\mathrm{Si} / \mathrm{SiO}_{2}$ platform. respectively, were extracted in the cross-sectional view [Figs. 1(e) and $1(\mathrm{f})$ ] from the bulk sample, transferred, and attached to a conventional omniprobe TEM grid. Afterward, the samples were additionally thinned to meet high-resolution TEM investigations. SEM images of both high-quality samples are presented in Fig. 3.

\section{Isolation of pillars by selective template back etch}

The last step in tubes fabrication was silicon back etch between structures. This was done by RIE using conventional equipment (RIE, from SPTS) with $\mathrm{SF}_{6}$ process gas [Fig. $1(\mathrm{~g})$ ], where the flow was kept constant at $35 \mathrm{sccm}$ at a substrate temperature of $20^{\circ} \mathrm{C}$. The coil power and process pressure were $30 \mathrm{~W}$ and 80 mTorr, respectively. This process proceeds with extreme selectivity toward the deposited ALD layer without any observable damage brought on the coaxial structure. It takes around $3 \mathrm{~min}$ to remove the Si core entirely. This etch time is not critical since the process basically stops at the $200 \mathrm{~nm}$ thin $\mathrm{SiO}_{2}$ interlayer of the SOI substrate. Further details regarding the sustainability of the structures in $\mathrm{SF}_{6}$ plasma environment are given elsewhere, ${ }^{9}$ where the fabrication of Al-doped $\mathrm{ZnO}$ nanotubes with $20 \mathrm{~nm}$ thick walls is described and provided detailed TEM images of side walls. The result of freestanding annealed tubes on the $\mathrm{Si} / \mathrm{SiO}_{2}$ surface is presented in Fig. 2(c), where the bird's-eye-view SEM image shows a well-preserved corner of the tube arrays.

\section{B. Characterization details}

The fabricated isolated coaxial tubes were thoroughly inspected using SEM. Figure 2(a) shows SEM images of the fabricated structure at the intermediate stage shown in Fig. $1(\mathrm{e})$. The top layer of $\mathrm{Al}_{2} \mathrm{O}_{3} /$ $\mathrm{ZnO} / \mathrm{Al}_{2} \mathrm{O}_{3}$ has been sputtered away, revealing a silicon matrix between coaxial nanotubes. After annealing at $800^{\circ} \mathrm{C}$ for $12 \mathrm{~h}$, the morphology of the nanotubes was changed [Fig. 2(b)]. Next, by applying reactive ion etching based on an $\mathrm{SF}_{6}$ continuous plasma etch, the $\mathrm{Si}$ core was removed, thus leaving porous freestanding coaxial structures in a periodic pattern on $\mathrm{Si} / \mathrm{SiO}_{2}$ platform [Fig. 2(c)].

Microstructural evolution inside the tubes was studied using several electron microscopy characterization techniques. The methods that have been applied for sample investigation inside a TEM
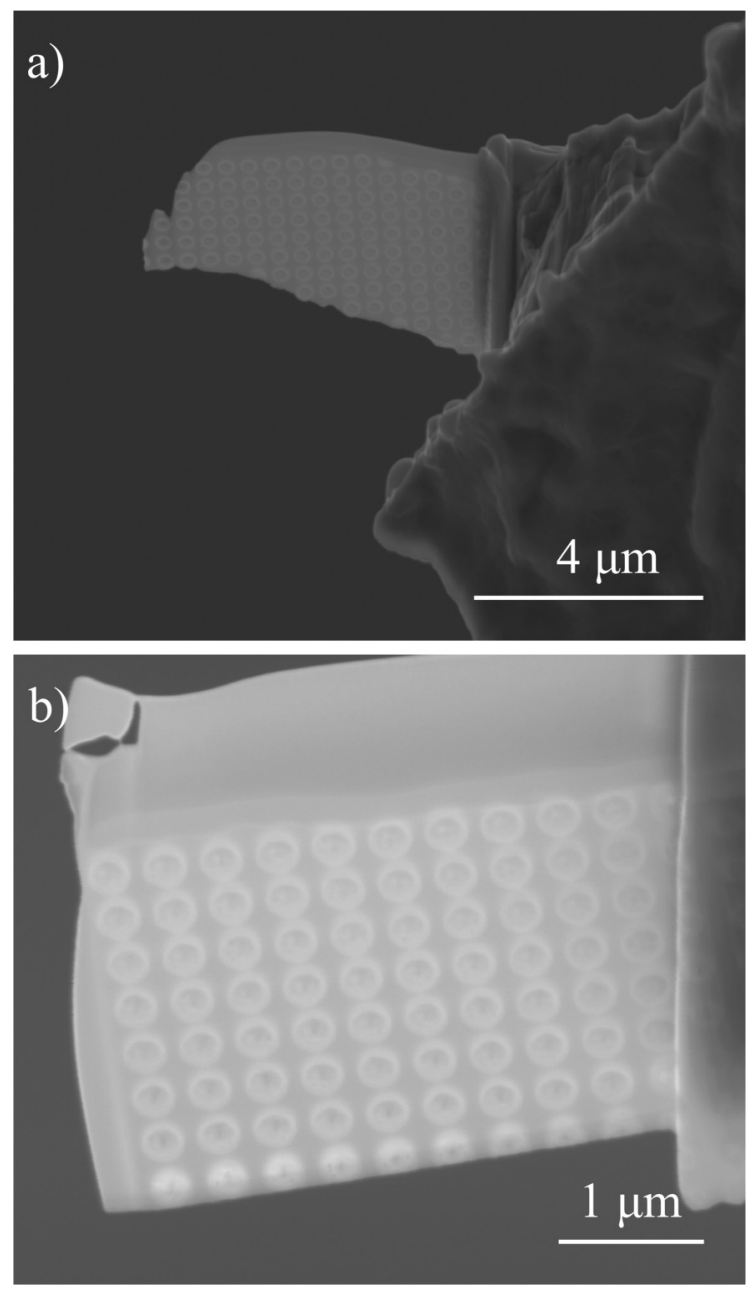

FIG. 3. FIB lamella extracted from the surfaces and attached to the TEM grid. (a) From sample before annealing. (b) From sample after annealing. 


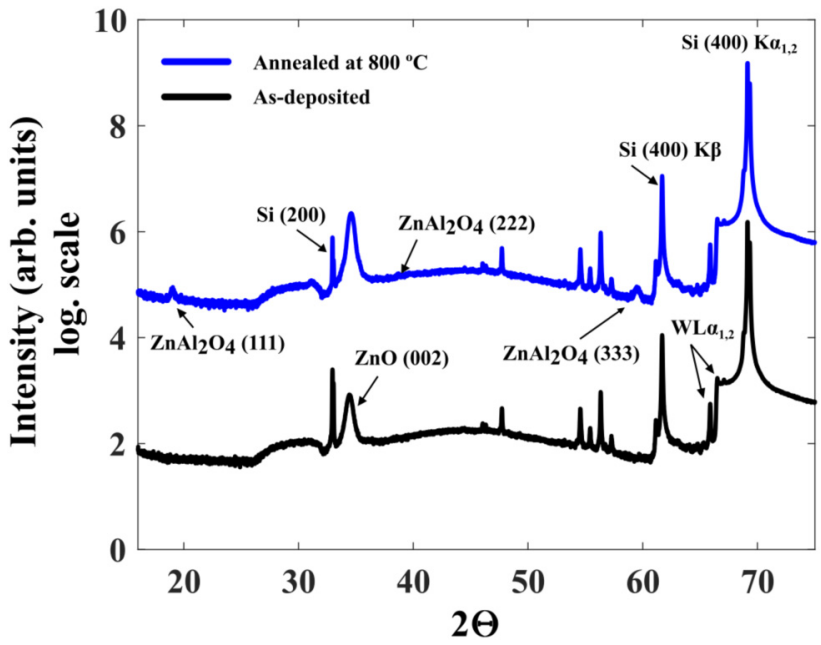

FIG. 4. XRD profiles of the flat films containing $\mathrm{Al}_{2} \mathrm{O}_{3} / \mathrm{ZnO} / \mathrm{Al}_{2} \mathrm{O}_{3}$ layers deposited on Si substrates with thicknesses 50,25 , and $50 \mathrm{~nm}$, respectively, before and after annealing. The scan of the sample after annealing indicates the formation of a $\mathrm{ZnAl}_{2} \mathrm{O}_{4}$ spinel phase as well as a shrinkage of the $\mathrm{ZnO}$ crystal lattice in the $c$-axis direction as a result of heat treatment.

instrument (FEI, Titan 80-300ST, $120 \mathrm{keV}$ ) include high-resolution transmission electron microscopy (HRTEM) and high angular annular dark-field and annular dark-field scanning transmission electron microscopy, abbreviated as HAADF-STEM and ADF-STEM, respectively. Elemental mapping was performed with energydispersive $\mathrm{x}$-ray spectroscopy (EDS) analysis (x-ray spectrometer from
Oxford Instrument integrated with the TEM equipment). Selected area electron diffraction (SAED) was carried out on tube samples, and conventional $\mathrm{x}$-ray diffraction (XRD) was performed to study the crystal orientations of the ALD deposited materials on planar $\mathrm{Si}$ (100) surfaces in the Bragg-Brentano geometry by a Rigaku SmartLab $3 \mathrm{~kW}$ diffractometer equipped with $\mathrm{Cu} \mathrm{K} \alpha$ x-ray source. The XRD profiles were scanned in steps of $0.002^{\circ} 2 \theta / s$.

\section{RESULTS AND DISCUSSION}

\section{A. XRD analysis of planar coatings}

To investigate crystallinity of the samples before and after annealing, the ALD coatings were deposited not only on the Si template [Fig. 1(c)] but also on flat silicon (100) surfaces. These samples have been annealed simultaneously with the tube structures. Figure 4 shows the XRD pattern of flat films before and after heat treatment. The annealed samples show the presence of (111) family peaks of $\mathrm{ZnAl}_{2} \mathrm{O}_{4}$, indicating the formation of the cubic spinel structure. ${ }^{35,36}$ Furthermore, the characteristic peak of the $\mathrm{ZnO}$ (002) reflection shifts to a higher $2 \theta$ angle, which indicates a reduction of the $\mathrm{ZnO}$ lattice constant. This can be attributed to the replacement of the larger $\mathrm{Zn}^{2+}$ ions by the smaller $\mathrm{Al}^{3+}$ ions in the lattice. ${ }^{9,37}$

\section{B. STEM analysis}

Figures 5(a)-5(c) show the initial nanotubes (ca. $300 \mathrm{~nm}$ diameter) surrounded by crystalline $\mathrm{Si}$ before annealing. The single pillars consist of a polycrystalline $\mathrm{ZnO}$ layer between amorphous $\mathrm{Al}_{2} \mathrm{O}_{3}$ oxide layers, with an empty core [Fig. 5(a)]. A higher magnification image [Fig. 5(b)] reveals that the $\mathrm{ZnO}$ layer is assembled from crystals of approximately $25 \times 10 \mathrm{~nm}^{2}$ oriented in the radial
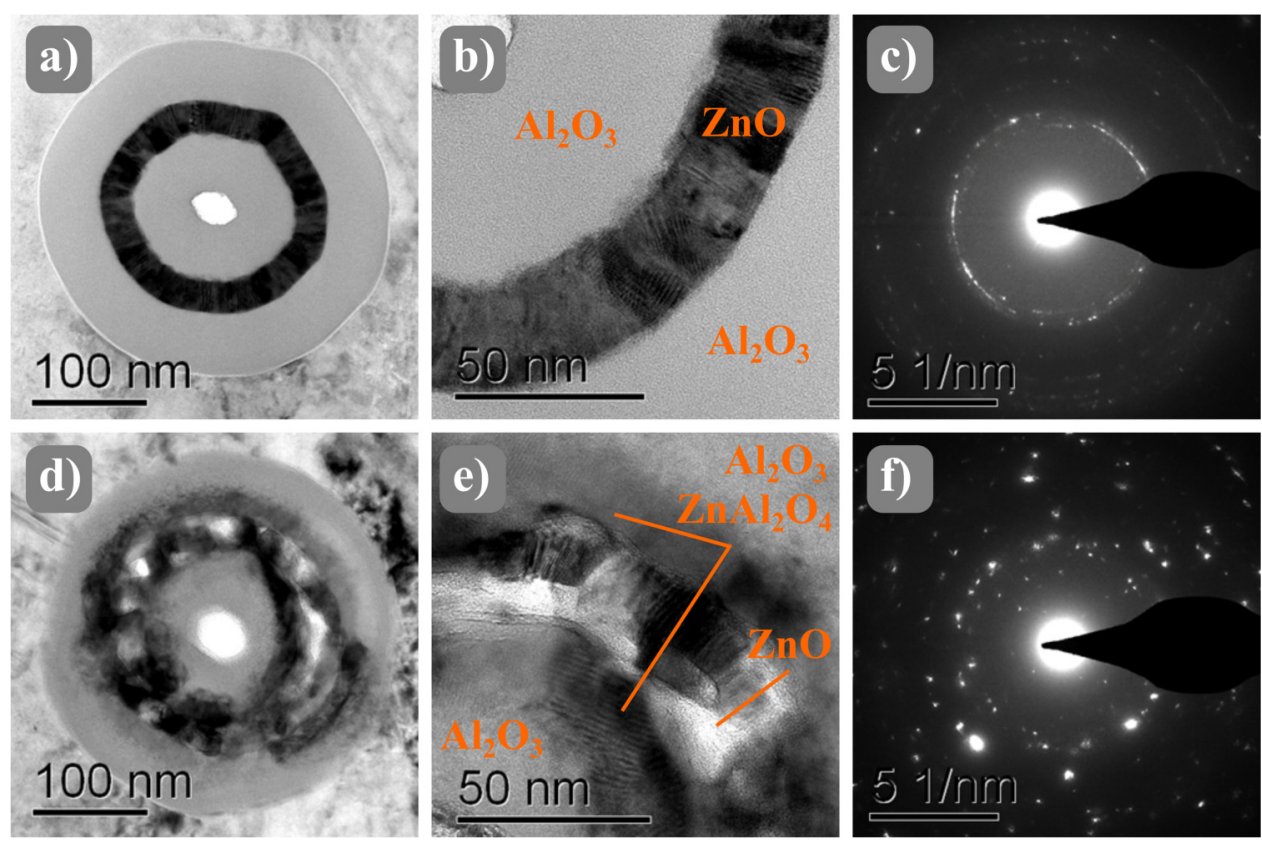

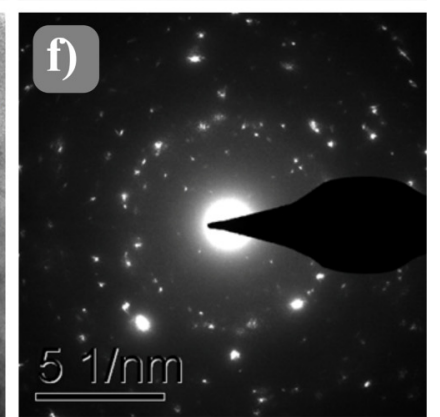

FIG. 5. (a) TEM image of crosssectional lamella sample showing one individual tube. (b) The corresponding HRTEM image of $\mathrm{ZnO}$ interlayer. (c) SAED pattern. (d)- (f) present the corresponding results for the annealed sample. 

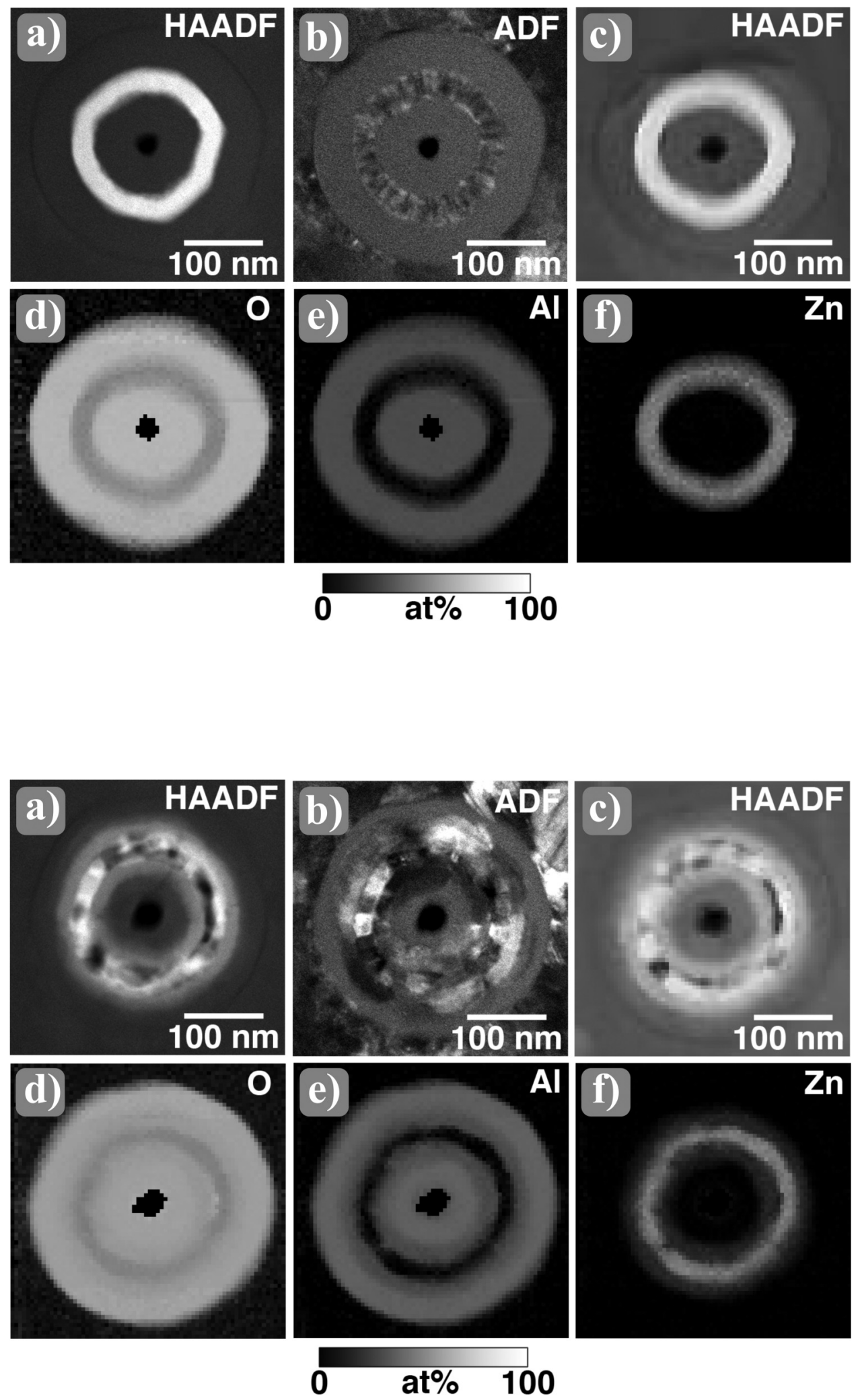

FIG. 6. STEM HAADF, ADF, and EDS quantitative maps of the initial sample. (a) HAADF image. (b) ADF image. (c) STEM HAADF image of the measured area and $(d)-(f)$ oxygen, aluminum, and zinc elemental maps.
FIG. 7. STEM HAADF, ADF, and EDS quantitative maps of the annealed sample. (a) HAADF image. (b) ADF image. (c) STEM HAADF image of the measured area and (d)-(f) oxygen, aluminum, and zinc elemental maps. 
direction. SAED from a single pillar confirms that $\mathrm{ZnO}$ is hexagonal, which is consistent with the XRD result.

Annealed pillars surrounded by crystalline Si exhibit different morphology and microstructure as summarized in Figs. 5(d)-5(f). The single nanowires consist of a porous $\mathrm{ZnO}$ layer sandwiched by (Zn-diffused) crystalline $\mathrm{ZnAl}_{2} \mathrm{O}_{4}$ layers next onto an $\mathrm{Al}_{2} \mathrm{O}_{3}$ layer [Fig. 5(d)]. The magnified TEM image [Fig. 5(e)] shows the structural evolution as a result of the annealing. The presence of voids in the $\mathrm{ZnO}$ region indicates diffusion of $\mathrm{ZnO}$ toward the initially amorphous $\mathrm{Al}_{2} \mathrm{O}_{3}$ layers. Diffraction patterns in SAED [Figs. 5(c) and $5(\mathrm{f})$ ] reveal a big difference between the initial and annealed tubes. The continuous rings of the initial sample, which represent polycrystalline $\mathrm{ZnO}$, are transformed into individual spots pattern, which can be interpreted as an increase in grain sizes of remaining $\mathrm{ZnO}$ and transformation to a new crystalline $\mathrm{ZnAl}_{2} \mathrm{O}_{4}$ spinel oxide.

For acquiring further elemental and microstructural information, STEM-HAADF (inner detector diameter, $87.7 \mathrm{mrad}$ ), STEM-ADF (inner and outer detector diameter, 9.7 and $41.7 \mathrm{mrad}$ ), and STEM-EDS were used. The HAADF and ADF were acquired from the same pillar at the same time. In the HAADF mode, the image contrast is sensitive to the mean atomic number and the specimen thickness so that higher mean atomic numbers or thicker regions appear brighter. In fact, the brightest contrast in the initial sample [Fig. 6(a)] corresponds to $\mathrm{ZnO}$, which has a heavier element than $\mathrm{Al}_{2} \mathrm{O}_{3}$ does. In the annealed sample [Fig. 7(a)], the $\mathrm{ZnO}$ layer has considerable contrast variation, originating from the presence of voids. The additional two layers of $\mathrm{ZnAl}_{2} \mathrm{O}_{4}$ that are located on both sides of the $\mathrm{ZnO}$ layer appear more clearly in Fig. 7(a). The $\mathrm{ZnAl}_{2} \mathrm{O}_{4}$ layers have continuous circular shapes with approximately $20 \mathrm{~nm}$ in height and lose image contrast gradually in the outer direction from the $\mathrm{ZnO}$ layer. This gradual change and vague phase boundary are also observed in the TEM image [Fig. 5(e)].

The ADF signal [Figs. 6(b) and 7(b)] has a more predominant contribution of diffracted electron beams over specimen thickness or composition. Therefore, the domainlike contrast suggests a polycrystalline structure, where each domain has the same diffracting condition. A uniform contrast would indicate either single crystalline or an amorphous phase. This supports the previous conclusion that the inner and outer shells of $\mathrm{Al}_{2} \mathrm{O}_{3}$ coatings remain amorphous after annealing, which was also supported by the conventional TEM [Fig. 5(e)]. Nevertheless, apparently, some crystals are extended to the $\mathrm{Al}_{2} \mathrm{O}_{3}$ region since the $\mathrm{ZnAl}_{2} \mathrm{O}_{4}$ thickness is almost constant and locally $\mathrm{ZnO}$ is missing [Fig. 7(b)]. This means that the diffusion may occur at an earlier stage due to gradual warm-up of the annealing furnace and low temperature (below $800^{\circ} \mathrm{C}$ ) or that a quick reaction with a narrow temperature window may take place.

\section{STEM-EDS investigations}

For STEM-EDS analysis, the specimens were tilted to $20^{\circ}$ about the horizontal axis for optimal geometry of the spectroscopy and the measured area presented in the tilted HAADF images [Figs. 6(c) and $7(c)]$. The quantitative maps of the initial and annealed specimens are presented in Figs. 6(d) $-6(\mathrm{f})$ and $7(\mathrm{~d})-7(\mathrm{f})$, respectively. The annealed tubes show more a homogeneous oxygen distribution and apparent $\mathrm{Zn}$ and $\mathrm{Al}$ concentration variations (at. \%) from the $\mathrm{ZnO}$ into the inner and outer directions due to diffusion. In addition to elemental maps presented in Figs. 6 and 7, the carbon signal was detected, which is conventional microscopy contamination and FIB lamella preparation.

Figure 8 shows the EDS quantitative line profile, which gives additional information on chemical distribution and diffusion. The annealing also affects the amorphous outer regions of alumina. Although the majority of the coatings appear to be preserved as the amorphous phase, the composition ( $\mathrm{Al}$ at. $\% / \mathrm{O}$ at. $\%=40 / 60$ ) is different from that in the initial tubes $(\mathrm{Al}$ at. $\% / \mathrm{O}$ at. $\%=30 / 70)$. This outcome is quite interesting since the ALD reaction based on water-TMA thermal interaction is expected to provide a stoichiometric $\mathrm{Al}_{2} \mathrm{O}_{3}$ film. Nevertheless, such high initial content of oxygen in the deposited alumina can be explained by the absorption of water inside the Si template during the ALD process. Postannealing removes this water, leaving the alumina with the predicted ratio (2:3). Moreover, Fig. 8(b) shows characteristic shoulders on $\mathrm{Zn}, \mathrm{Al}$,
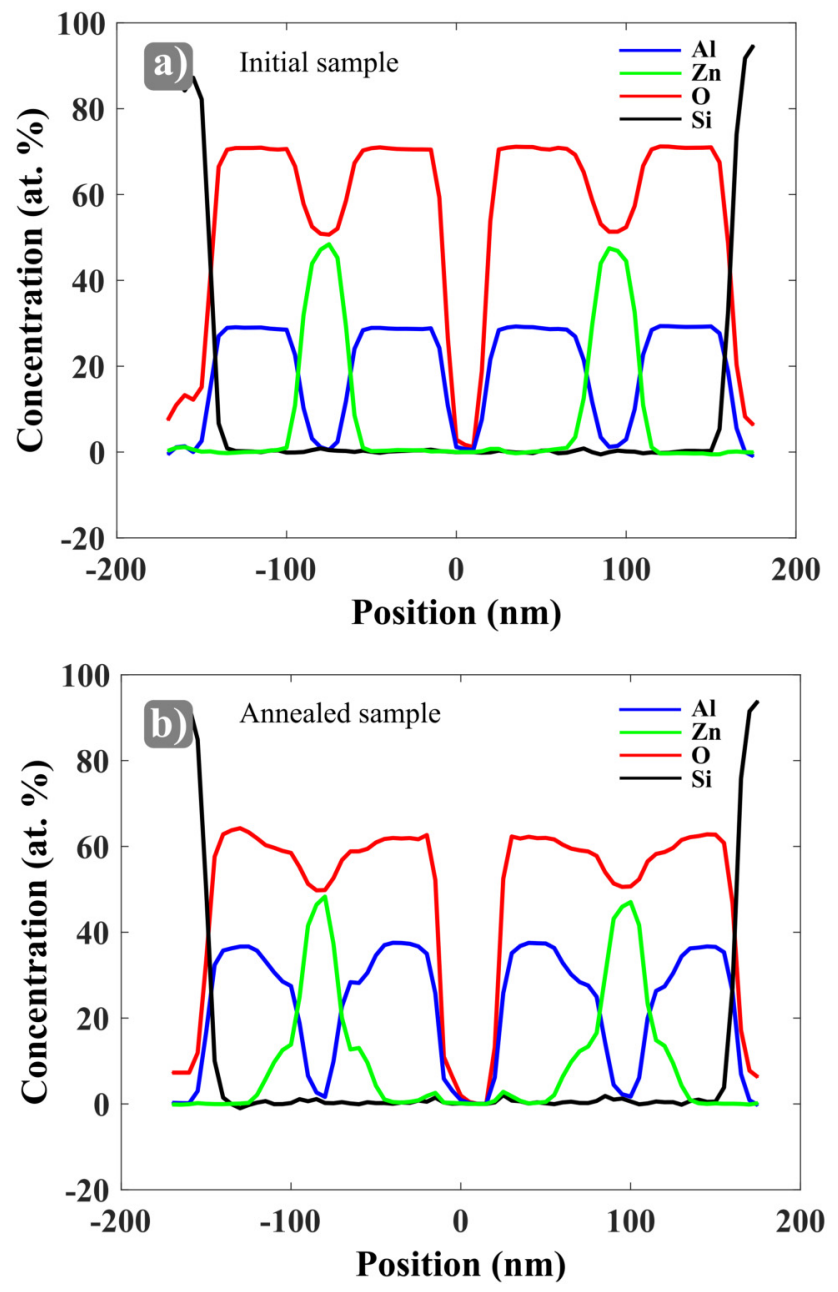

FIG. 8. EDS quantitative line profiles. (a) Initial sample and (b) annealed sample. 
and $\mathrm{O}$ elemental line profiles of the annealed sample, which is a consequence of the diffusion process (the Kirkendall effect). Composition stoichiometry extracted from Fig. 8(b) highly suggests the formation of $\mathrm{ZnAl}_{2} \mathrm{O}_{4}$ spinel. The thickness of the spinel layer can be estimated from the HAADF image of the annealed sample [Fig. 7(a)], and the chemical composition is provided by EDS [Fig. 8(b)]. Despite the excess of initial $\mathrm{Al}_{2} \mathrm{O}_{3}$ and $\mathrm{ZnO}$ and prolonged annealing, it does not exceed $20 \mathrm{~nm}$. This limitation needs to be addressed in future fabrication designs.

\section{SUMMARY AND CONCLUSIONS}

To summarize, high aspect ratio arrays of isolated nanotubes were fabricated by combining deep-UV lithography, ALD, and DRIE techniques. The diffusion of $\mathrm{ZnO}$ into amorphous alumina was studied by various TEM techniques using FIB extracted lamellae. The work demonstrates a new and generic fabrication method to create and thermally manipulate the inner composition of alldielectric multilayered nanotubes. Realized annealed structures clearly show the diffusion of $\mathrm{ZnO}$ into surrounding amorphous alumina and partial transformation to the crystalline $\mathrm{ZnAl}_{2} \mathrm{O}_{4}$ spinel structure. It demonstrates that a complex material multilayer can undergo multidirectional diffusion and formation of the prescribed periodic spinel. The total thickness of the $\mathrm{ZnAl}_{2} \mathrm{O}_{4}$ region is approximately $20 \mathrm{~nm}$.

As for the outlook, further work is needed for understanding the details of the diffusion kinetics. Improved annealing conditions and posttreatment methods need to be developed if fully separated, continuous, and pin-hole free multilayers are required. Additionally, in the ALD deposition step, other precursors such as $\mathrm{O}_{3}$ need to be considered to eliminate the presence of absorbed water in the structures and reduce analysis complexity. Further studies on the applications of these transformed nanotubes are in progress.

\section{ACKNOWLEDGMENTS}

The authors gratefully acknowledge Takeshi Kasama for all the work done on TEM analysis of the prepared structures. Without his help and knowledge, it would not be possible to complete this work. The authors would like to thank process specialists M. Keil and E. Khomtchenko from National Centre for Nano Fabrication and Characterization (DTU Nanolab) for the support related to deep-UV lithography. The authors would like to acknowledge Villum Fonden (DarkSILD Project No. 11116) and Direktør Ib Henriksens Fond, Denmark for financial support.

\section{REFERENCES}

${ }^{1}$ W. Cai and V. Shalaev, Optical Metamaterials: Fundamentals and Applications (Springer, New York, NY, 2010).

${ }^{2}$ D. Lu and Z. Liu, Nat. Commun. 3, 1205 (2012).

${ }^{3}$ T. Repän, A. V. Lavrinenko, and S. V. Zhukovsky, Opt. Express 23, 25350 (2015).

${ }^{4}$ A. Poddubny, I. Iorsh, P. Belov, and Y. Kivshar, Nat. Photonics 8, 78 (2013).

${ }^{5}$ L. Ferrari, C. Wu, D. Lepage, X. Zhang, and Z. Liu, Prog. Quantum Electron. 40, 1 (2015).

${ }^{6}$ O. Takayama and A. V. Lavrinenko, J. Opt. Soc. Am. B 36, F38 (2019).
${ }^{7}$ A. V. Kabashin, P. Evans, S. Pastkovsky, W. Hendren, G. A. Wurtz, R. Atkinson, R. Pollard, V. A. Podolskiy, and A. V. Zayats, Nat. Mater. 8, 867 (2009).

${ }^{8}$ C. T. Riley, J. S. T. Smalley, K. W. Post, D. N. Basov, Y. Fainman, D. Wang, Z. Liu, and D. J. Sirbuly, Small 12, 892 (2016).

${ }^{9}$ E. Shkondin, O. Takayama, M. E. Aryaee Panah, P. Liu, P. V. Larsen, M. D. Mar, F. Jensen, and A. V. Lavrinenko, Opt. Mater. Express 7, 1606 (2017).

${ }^{10}$ O. Takayama et al., ACS Photonics 4, 2899 (2017).

${ }^{11}$ A. A. High, R. C. Devlin, A. Dibos, M. Polking, D. S. Wild, J. Perczel, N. P. De Leon, M. D. Lukin, and H. Park, Nature 522, 192 (2015).

${ }^{12}$ G. V. Naik, B. Saha, J. Liu, S. M. Saber, E. A. Stach, J. M. K. Irudayaraj, T. D. Sands, V. M. Shalaev, and A. Boltasseva, Proc. Natl. Acad. Sci. U.S.A. 111, 7546 (2014).

${ }^{13}$ S. V. Zhukovsky, A. Andryieuski, O. Takayama, E. Shkondin, R. Malureanu, F. Jensen, and A. V. Lavrinenko, Phys. Rev. Lett. 115, 177402 (2015).

${ }^{14} \mathrm{~K}$. V. Sreekanth, Y. Alapan, M. El Kabbash, E. Ilker, M. Hinczewski, U. A. Gurkan, A. De Luca, and G. Strangi, Nat. Mater. 15, 621 (2016).

15. Sukham, O. Takayama, A. V. Lavrinenko, and R. Malureanu, ACS Appl. Mater. Interfaces 9, 25049 (2017).

${ }^{16}$ K.-H. Kim, Y.-S. No, S. Chang, J.-H. Choi, and H.-G. Park, Sci. Rep. 5, 16027 (2015)

${ }^{17}$ P. Moitra, Y. Yang, Z. Anderson, I. I. Kravchenko, D. P. Briggs, and J. Valentine, Nat. Photonics 7, 791 (2013).

${ }^{18}$ E. Shkondin, T. Repän, O. Takayama, and A. V. Lavrinenko, Opt. Mater. Express 7, 4171 (2017).

${ }^{19}$ M. A. Baqir, A. Farmani, T. Fatima, M. R. Raza, S. F. Shaukat, and A. Mir, Appl. Opt. 57, 9447 (2018).

${ }^{20}$ E. Shkondin, T. Repän, M. E. Aryaee Panah, A. V. Lavrinenko, and O. Takayama, ACS Appl. Nano Mater. 1, 1212 (2018).

${ }^{21}$ Y. Yang, R. Scholz, H. J. Fan, D. Hesse, U. Gösele, and M. Zacharias, ACS Nano 3, 555 (2009).

${ }^{22}$ Y. Yang, R. Bin Yang, H. J. Fan, R. Scholz, Z. Huang, A. Berger, Y. Qin, M. Knez, and U. Gösele, Angew. Chem. Int. Ed. 49, 1442 (2010).

${ }^{23}$ H. Fan, M. Knez, R. Scholz, K. Nielsch, E. Pippel, D. Hesse, U. Gösele, and M. Zacharias, Nanotechnology 17, 5157 (2006).

${ }^{24}$ F. Güder, Y. Yang, S. Goetze, A. Berger, N. Ramgir, D. Hesse, and M. Zacharias, Small 6, 1603 (2010).

${ }^{25}$ F. Güder, Y. Yang, S. Goetze, A. Berger, R. Scholz, D. Hiller, D. Hesse, and M. Zacharias, Chem. Mater. 23, 4445 (2011).

${ }^{26}$ A. A. El Mel, R. Nakamura, and C. Bittencourt, Beilstein J. Nanotechnol. 6, 1348 (2015).

${ }^{27}$ R. L. Puurunen, J. Appl. Phys. 97, 121301 (2005).

${ }^{28}$ S. M. George, Chem. Rev. 110, 111 (2010).

${ }^{29}$ V. Cremers, R. L. Puurunen, and J. Dendooven, Appl. Phys. Rev. 6, 021302 (2019).

${ }^{30}$ B. Wu, A. Kumar, and S. Pamarthy, J. Appl. Phys. 108, 051101 (2010).

${ }^{31}$ E. Shkondin, O. Takayama, J. M. Lindhard, P. V. Larsen, M. D. Mar, F. Jensen, and A. V. Lavrinenko, J. Vac. Sci. Technol. A 34, 031605 (2016).

${ }^{32}$ B. Chang, P. Leussink, F. Jensen, J. Hübner, and H. Jansen, Microelectron. Eng. 191, 77 (2018).

${ }^{33} \mathrm{~B}$. Chang, F. Jensen, J. Hübner, and H. Jansen, J. Micromech. Microeng. 28, 105012 (2018).

${ }^{34}$ V. Miikkulainen, M. Leskela, M. Ritala, and R. L. Puurunen, J. Appl. Phys. 113, 021301 (2013).

${ }^{35}$ Q. Hou, F. Meng, and J. Sun, Nanoscale Res. Lett. 8, 144 (2013).

${ }^{36} \mathrm{Z}$. Bi, R. Zhang, X. Wang, S. Gu, B. Shen, Y. Shi, Z. Liu, and Y. Zheng, J. Am. Ceram. Soc. 86, 2059 (2003).

${ }^{37}$ A. Crovetto, T. S. Ottsen, E. Stamate, D. Kjær, J. Schou, and O. Hansen, J. Phys. D Appl. Phys. 49, 295101 (2016). 